\title{
Composite Polymer Electrolyte based on Liquid Crystalline Copolymer with High-temperature Stability and Bendability for All-solid-state Lithium-ion Batteries
}

\author{
Xiaoyan Cao, Jiaming Cheng, Xiubo Zhang, Dan Zhou, Yongfen Tong* \\ School of Environmental and Chemical Engineering, Nanchang Hangkong University, 696 Fenghe \\ South Avenue, Nanchang 330063, China \\ *E-mail: tongyongfen@ @ nchu.edu.cn
}

doi: $10.20964 / 2020.01 .32$

Received: 16 September 2019 / Accepted: 2 November 2019 / Published: 30 November 2019

\begin{abstract}
In this study, a novel composite polymer electrolyte consist of 8-arm block liquid crystalline copolymer (8-PEG-MALC), 8-arm poly(ethylene glycol) (8-PEG), polyethylene (glycol) diacrylate (PEGDA) and bistrifluoromethanesulfonimide lithium salt (LiTFSI) was prepared successfully. The branching 8-PEG ensure high ionic conductivity of the all solid state polymer, crosslinking agent PEGDA endow good mechanical property, and 8-arm block liquid crystalline copolymer with a birefringent mesogens to tune the morphology of the composite polymer electrolytes. The polymer electrolytes can form a transparent and flexible film with nanoscale microphase separation structure, which creating well-defined ion conducting channels. The electrochemical properties of composite polymer electrolytes are analyzed and the highest ionic conductivity reaches $6.2 \times 10^{-5} \mathrm{~S} \mathrm{~cm}^{-1}$ at room temperature after annealed from fixed temperature. It also displays high temperature stability up to $150^{\circ} \mathrm{C}$, which is higher than traditional electrolytes. More intriguingly, the assembled $\mathrm{LiFePO}_{4} / \mathrm{Li}$ cells using the composite polymer electrolytes exhibit good charge/discharge cycles at $95^{\circ} \mathrm{C}$. The good electrochemical properties, temperature stability and bendability of the composite polymer electrolytes indicate it potentially as a very promising material for all-solid-state flexible lithium ion batteries.
\end{abstract}

Keywords: self-assemble; composite polymer electrolytes; bendability; lithium-ion batteries

\section{$\underline{\text { FULL TEXT }}$}

(C) 2020 The Authors. Published by ESG (www.electrochemsci.org). This article is an open access article distributed under the terms and conditions of the Creative Commons Attribution license (http://creativecommons.org/licenses/by/4.0/). 